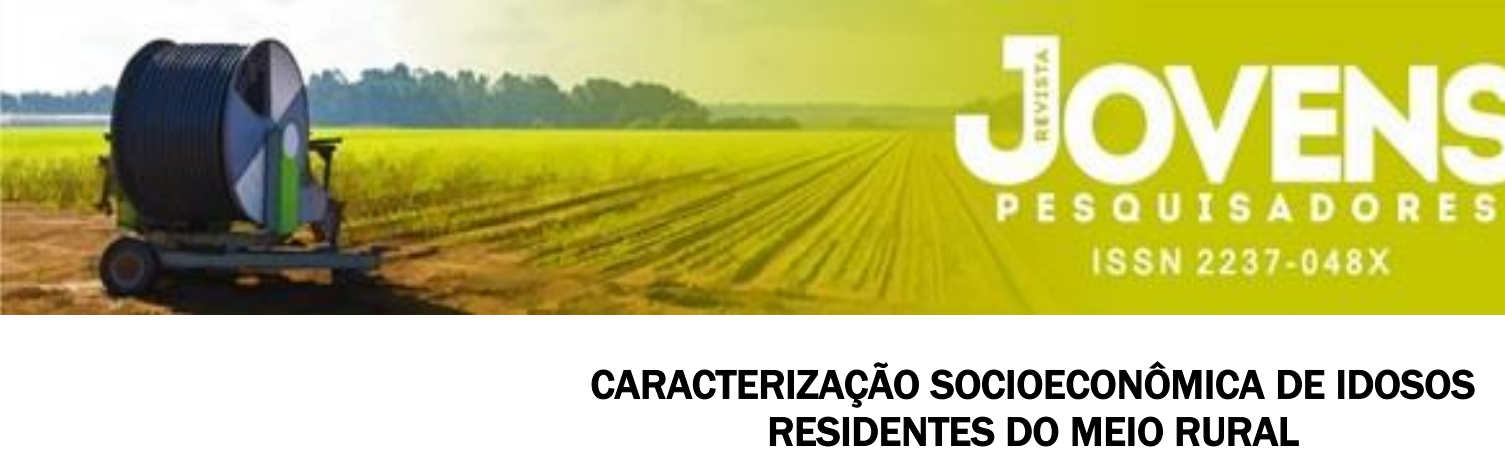

\title{
CARACTERIZAÇÃO SOCIOECONÔMICA DE IDOSOS RESIDENTES DO MEIO RURAL
}

\author{
ROSA, D. L. F.1; AREOSA, S.V.C. ${ }^{2}$
}

PALAVRAS CHAVE: Envelhecimento humano. Velhice Rural. Renda.

\begin{abstract}
RESUMO
O Envelhecimento da população brasileira apresenta desafios em termos de políticas e ações que deem suporte para essa nova demanda populacional. Sendo assim, conhecer as diferentes velhices do país é parte fundamental deste processo. Neste recorte do projeto de pesquisa intitulado "Estudo Socioeconômico e Demográfico da População Idosa no Meio Rural do Município de Santa Cruz do Sul”, serão apresentados dados quantitativos obtidos através de um questionário socioeconômico e demográfico realizado com 236 idosos de 7 distritos rurais do município, com o objetivo de desvelar as características econômicas presentes neste contexto. A análise dos dados evidencia que a maior parte dos idosos tem na aposentadoria a sua principal fonte de renda e que apesar da seguridade financeira que a mesma oferece, relatam a falta de dinheiro para suprir necessidades básicas, como alimentação e saúde, optando então por continuar trabalhando ou mantendo cultivos para sua subsistência.
\end{abstract}

\section{SOCIOECONOMIC CHARACTERIZATION OF ELDERLY RESIDENTS OF THE RURAL ENVIRONMENT}

KEYWORDS: Human aging. Rural elderly. Income.

\begin{abstract}
Aging of the Brazilian population presents a challenge in create policies and actions that support this new population demand. Therefore, knowing the different old ages of the country is fundamental. In this fragment of the research project, titled Socioeconomic and Demographic Study of the Elderly Population in the Municipality of Santa Cruz do Sul, will be present quantitative data obtained through a socioeconomic and demographic questionnaire carried out with 236 elderly people from seven rural districts of the municipality. The objective is unveiling the economic characteristics present in this context. Data analysis shows that most of the elderly have the main source of income in their retirement and that despite the financial security it offers, they report lacking money to meet basic needs such as food and health, so they choose to continue working or maintaining crops for subsistence.
\end{abstract}

\footnotetext{
${ }_{1}$ Acadêmico do curso de Psicologia na Universidade de Santa Cruz do Sul.

2 Dra. em Serviço Social, Professora do Departamento de Psicologia, do Programa de Mestrado e Doutorado em Desenvolvimento Regional e Coordenadora do Mestrado Profissional em Psicologia na Universidade de Santa Cruz do Sul.
} 


\section{INTRODUÇÃO}

O Brasil passa por uma significativa mudança em sua estrutura populacional, econômica e social, isto se deve a fatores como a queda das taxas de fertilidade e o avanço das tecnologias médicas, com a melhora na qualidade de vida e, por conseguinte o aumento da população idosa (CAMARANO; FERNANDES, 2016). Segundo dados divulgados pela Pesquisa Nacional por Amostra de Domicílios (PNAD) em 2017 o número de idosos no país chegou a 30,2 milhões. Este fato, dá fim a visão do Brasil como um país jovem e de jovens. A realidade é de uma população que caminha rapidamente para se consolidar como uma população envelhecida, com grandes problemas sociais e econômicos (BRITO, 2018).

Essa mudança na expectativa de vida é um fenômeno que rapidamente transforma a sociedade. No Brasil, em 1950, uma criança com 10 anos tinha uma expectativa de vida de 53 anos; em 2015, passou a ser de 67 anos (CAMARANO; FERNANDES, 2016). Segundo o relatório de 2015 da Organização Mundial Da Saúde (OMS), há mais de 500 mil pessoas no mundo com mais de 100 anos. Esse número deverá duplicar a cada 10 anos, e a população mundial com mais de 60 anos deverá passar para 2 bilhões até 2050 . Tendo em vista este cenário, cada vez mais se fazem necessárias a criação de políticas, programas e ações que assegurem direitos a esta nova composição populacional.

Para isto faz-se necessário estudar de maneira aprofundada o envelhecimento no contexto brasileiro, pois o mesmo exige um conhecimento amplo sobre os espaços geográficos onde os idosos se encontram, existem realidades muito particulares, tanto econômicas e sociais quanto culturais (ALCÂNTARA, 2016), e ainda, locais de difícil acesso, como às localidades rurais, com menos disponibilidade de recursos e precariedade de políticas públicas, ademais, com pouca produção científica a respeito (BITENCOURT; DALTO, 2016).

Nos espaços rurais, as transformações sociais e econômicas também aumentaram, uma vez que as trajetórias de vida dos idosos, já acumularam prejuízos, como trabalhar sem registro em carteira e muitas vezes sem remuneração, iniciar a vida laboral precocemente, ter jornadas duplas e muitas outras irregularidades (TONEZER; TRZCINSKI; MAGRO, 2017). Aqui o processo de envelhecimento traz à tona discussões e debates sobre um ator social cada vez mais presente, o idoso aposentado rural, que vem influenciando o campo, desde o resgate da Constituição de 1988, quando o trabalhador rural foi incluído no Regime Geral da Previdência Social.

Em termos econômicos, o que se conhece é que neste espaço rural a aposentadoria possui uma importância significativa, já que ela garante ao idoso do campo o seu sustento e provimento das necessidades (ALCÂNTARA, 2016). A aposentadoria rural, configura um benefício que melhora a renda destes idosos em seus domicílios, já que antes dependiam basicamente da renda advinda do trabalho agrícola, que nem sempre é estável e garantida (BITENCOURT; DALTO, 2016).

No meio rural, homens (acima de 60 anos) e mulheres (acima de 55 anos), que comprovem qualquer tipo de trabalho agrícola de sustento passam a ter acesso a uma aposentadoria no valor de um salário mínimo (R\$998,00 em 2019). Com esta receita adicional, o idoso também passa a ser ator importante na organização financeira do lar, já que contribui mensalmente e de maneira significativa (TAVARES et. al. 2011). Porém, mesmo que comecem a receber o benefício financeiro, muitos idosos continuam trabalhando, devido a gastos que vão além do valor recebido, como forma de complementar sua renda.

Como pouco se conhece desta realidade e também partindo da premissa que a maior parte das pesquisas sobre pessoas idosas e renda se dirigem ao contexto urbano (havendo então uma lacuna de estudos que contemplem os idosos moradores do campo), o presente artigo apresentará um recorte do projeto de 
pesquisa intitulado "Estudo Socioeconômico e Demográfico da População Idosa no Meio Rural do Município de Santa Cruz do Sul”, realizado pela Universidade de Santa Cruz do Sul através de financiamento captado junto ao Conselho Municipal do Idoso de Santa Cruz do Sul, com o objetivo de elucidar as condições econômicas dos idosos no meio rural do município. As diferentes configurações financeiras encontradas serão discutidas e articuladas com outros estudos já publicados a partir de pesquisadores da área do envelhecimento humano.

\section{METODOLOGIA}

O estudo está ancorado na abordagem quantitativa e os dados que serão apresentados a seguir foram coletados a partir de um questionário socioeconômico e demográfico, baseado no modelo utilizado pelo Instituto Brasileiro de Geografia e Estatística (IBGE) para o censo demográfico de 2010, contendo questões relativas à idade, sexo, estado civil, saúde, escolaridade, moradia, renda, ocupação (atual) e religião. Para a obtenção dos dados deste estudo foram selecionadas as respostas das seguintes questões: "você é aposentado?; fontes de renda atuais?; qual sua renda mensal?; renda familiar?; você tem dinheiro suficiente para satisfazer suas necessidades?;se não, para o que falta dinheiro? ".

Ao todo participaram da pesquisa 236 idosos, 71 homens e 165 mulheres, entre 60 e 96 anos de idade. Essa amostra equivale a cerca de $10 \%$ do total de idosos em cada localidade, ou seja, dos sete distritos rurais do município: Alto Paredão; Saraiva; São Martinho; Rio Pardinho; Boa Vista; Monte Alverne e São José da Reserva. Os questionários foram aplicados pelo grupo de pesquisa em Unidades Básicas de Saúde, Estratégias Saúde da Família (ESF), Hospitais, grupos de convivência e em residências, por agentes comunitários nas localidades mais distantes ou pelo próprio grupo de pesquisa. Os idosos que concordaram em participar da pesquisa assinaram o termo de consentimento livre e esclarecido, dando o seu assentimento. A busca compreendeu o período de julho de 2017 até junho de 2018. Os dados foram tratados através do software Statistical Package for Social Sciences (SPSS) - Versão 18.0. Os resultados foram analisados por meio de estatística descritiva (frequência e percentual), sendo apresentados em tabelas para melhor visualização.

\section{RESULTADOS E DISCUSSÕES}

A Previdência Social avançou significativamente no meio rural brasileiro a partir do final do século XX. 0 benefício da aposentadoria rural veio a tornar-se uma política pública importante, geradora de resultados socioeconômicos positivos, que vão além dos beneficiários do campo, pois acaba envolvendo toda a estrutura econômica dos pequenos municípios rurais do país (BITENCOURT; DALTO, 2016). Isto porque ao receberem o rendimento fixo de um salário mínimo mensal, as famílias dos aposentados rurais passaram a viver melhor, com maior poder de compra e segurança financeira, evoluindo suas condições de moradia e saúde, passando também assim a movimentar economicamente a região onde vivem (OLIVEIRA; AQUINO, 2017). Na tabela a seguir, se observa que a maioria dos idosos da amostra já estão aposentados: 
Tabela 1 - Você é aposentado?

\begin{tabular}{c|c|c}
\hline Você é aposentado? & $\begin{array}{c}\text { Número de idosos } \\
\text { entrevistados }\end{array}$ & Porcentagem Válida \\
\hline Sim & 231 & 97,9 \\
\hline Não & 5 & 2,1 \\
\hline Total & 236 & 100,0 \\
\hline
\end{tabular}

Fonte: Coleta de Dados da pesquisa - 2018.

Ou seja, 97,9\% dos respondentes recebem o benefício mensal e se tratando do contexto rural, aposentarse possibilita uma garantia de renda que até então era desconhecida por muitos trabalhadores, já que a maioria costumava possuir arrecadação semestral ou anual, pois variava de acordo com o período das colheitas (OLIVEIRA; AQUINO, 2017). Sendo assim, o agricultor não possuía uma renda fixa. 0 valor mínimo recebido, impulsiona a economia local dos pequenos municípios rurais, pois esta renda é gasta amplamente nos comércios locais, proporcionando aumento dos estabelecimentos, de emprego, e maior movimentação financeira, devido a garantia do pagamento mensal do benefício (AUGUSTO; RIBEIRO, 2005).

O sistema de aposentadoria rural funciona da seguinte forma: Os trabalhadores rurais participam do sistema de previdência e contribuem para o Regime Geral de Previdência Social (RGPS), por duas modalidades de benefício: o de contribuição obrigatória e o de contribuição facultativa. Neste primeiro, os trabalhadores rurais com carteira assinada, contribuem para a previdência social durante suas vidas laborais e na inatividade tem direito a aposentadoria, recebendo até $100 \%$ do salário-de-benefício. A segunda categoria abrange, principalmente, os trabalhadores rurais classificados como segurados especiais. Nesta segunda categoria, são considerados os trabalhadores rurais informais, que participam da agricultura familiar ou da agricultura de subsistência. Estes, apesar de não contribuírem continuamente para a previdência social, possuem o direito de receber a aposentadoria por idade ou por invalidez no valor de um salário mínimo, mediante comprovação de exercício na atividade rural (SOUZA; STADUTO; KRETER, 2017).

A Previdência Social no Brasil demorou a alcançar os espaços rurais. Somente com a Constituição de 1988 e com a implementação das leis de custeio do sistema nos anos 1990 é que ocorreram algumas mudanças normativas visando a atender as especificidades dos trabalhadores do campo (OLIVEIRA; AQUINO, 2017). Em 1992, com a aplicação das leis complementares № 8.212 e N8.213 de 24 de junho de 1991 que foram instituídos o Plano de Custeio e o Plano de Benefícios, promovendo a universalização do programa previdenciário rural brasileiro, com a formulação destas três regras: equiparação do acesso ao benefício para homens e mulheres; redução da idade mínima para aposentadoria,60 anos para os homens e 55 para mulheres (uma das razões para o menor tempo de contribuição exigido para estas é o custo gerado pela maternidade); e o piso de um salário mínimo para aposentadorias e pensões - um acréscimo em relação ao piso de meio salário mínimo até então vigente (BITENCOURT; DALTO, 2016).

Recentes estudos demonstram que as aposentadorias impactam diretamente na redução da pobreza no meio rural brasileiro, à medida que facilitam a reprodução econômica de uma parcela da população que, em muitos casos, não teria condições de sobreviver dignamente sem a proteção proporcionada pela política social (OLIVEIRA; AQUINO, 2017).

Um dos pontos fundamentais desta pesquisa é analisar a natureza dos rendimentos das famílias destes idosos rurais, incluindo todas as fontes de entradas monetárias em seus domicílios. Na tabela 2, é possível 
observar que a aposentadoria também é de onde advém a principal fonte de renda da população idosa do município:

Tabela 2 - Fontes de Renda

\begin{tabular}{c|c|c|c}
\hline Fontes de Renda & $\begin{array}{c}\text { Número de } \\
\text { respostas }\end{array}$ & Porcentagem & Porcentagem de casos \\
\hline Aposentadoria & 232 & $65,0 \%$ & $98,3 \%$ \\
\hline Pensão & 49 & $13,7 \%$ & $20,8 \%$ \\
\hline Trabalho atual & 38 & $10,6 \%$ & $16,1 \%$ \\
\hline $\begin{array}{c}\text { Ajuda de filhos } \\
\text { parentes }\end{array}$ & 14 & $3,9 \%$ & $5,9 \%$ \\
\hline $\begin{array}{c}\text { Produção rural } \\
\text { Aluguéis }\end{array}$ & 10 & $2,8 \%$ & $4,2 \%$ \\
\hline Terras arrendadas & 8 & $2,2 \%$ & $3,4 \%$ \\
\hline Herança & 5 & $1,4 \%$ & $2,1 \%$ \\
\hline Total & 357 & $0,3 \%$ & $0,4 \%$ \\
\hline
\end{tabular}

Fonte: Coleta de Dados da pesquisa - 2018.

Vale considerar que temos duas colunas com as porcentagens, à primeira diz respeito às respostas, considerando o total de respostas e no final soma $100 \%$, no caso da segunda coluna com a porcentagem de casos, a porcentagem total dará mais que $100 \%$, uma vez que ela está se referindo a quantidade de respondentes que citaram cada provento, sendo que algumas pessoas além da aposentadoria ou pensão, ainda trabalham ou tem outras fontes financeiras (sendo uma questão de múltipla escolha). A partir desta análise de frequência de múltiplas respostas sobre os ganhos dos idosos (cabe ressaltar que foram consideradas respostas afirmativas sobre ganhos próprios, de cônjuges e familiares que residem junto aos idosos) é possível apontar que a aposentadoria surge como principal fonte de renda sendo mencionada por 232 idosos (98,3\% das afirmativas).

Estes dados evidenciam a ampla diferença da aposentadoria quando comparada a outras fontes financeiras, como as pensões previdenciárias, por exemplo, segunda maior fonte de rendimentos citada com $\mathbf{2 0 , 8}$ \% de respostas. As atividades ligadas ao campo, como produção e trabalho rural vem em seguida, somando 20,3\%. A representatividade observada sobre a renda dos benefícios previdenciários rurais confirma os recentes estudos, de que os idosos aposentados da área rural, em todo o território nacional, têm como renda principal, a aposentadoria (BITENCOURT; DALTO, 2016).

Características semelhantes à do município deste estudo foram encontradas na pesquisa de 2006 dos autores Augusto e Ribeiro, ao analisarem os efeitos das aposentadorias rurais, nos domicílios e no comércio no município de Medina, nordeste de Minas Gerais. De acordo com as informações encontradas, as principais fontes de renda das famílias dos aposentados rurais de Medina provêm da aposentadoria, dos ganhos com a produção agrícola familiar e das pensões previdenciárias. Neste espaço a fonte de renda mais significativa também é a aposentadoria rural, responsável por mais de $50 \%$ da renda em todas as famílias. 0 benefício chega a representar $100 \%$ da renda de $50 \%$ do total de domicílios pesquisados.

Nas investigações conduzidas por Alcântara (2016) é notório o quão importante é a renda advinda das aposentadorias por idade rural, uma vez que, apesar de os valores serem considerados modestos, se tornam a 
principal fonte de renda de um grupo familiar, representando também para os idosos uma certa garantia e independência econômica em relação a filhos e parentes.

\begin{abstract}
O significado da conquista da aposentadoria consiste na segurança de que um tempo de grande privação não se repetirá, e o alimento não Ihes faltará.[...] Assim, embora possa parecer um valor pequeno, a aposentadoria Ihes confere dignidade, uma vez que, de acordo com estes interlocutores, eles haviam sido privados de uma das necessidades básicas vitais, isto é, comer. Foi frequente ouvir dos aposentados rurais sobre a satisfação em que se encontram ao compararem o presente com o passado, visto que, hoje, o "aposento" garante o sustento de toda a família, ao passo que, no passado, inexistia esse benefício, sendo comum, então, a presença dos velhos pedintes de porta em porta. Assim, a Previdência é a principal fonte de renda dos idosos brasileiros (ALCÂNTARA; 2016, p. 336).
\end{abstract}

Abaixo, a tabela 3 mostra que os ganhos mensais dos idosos do estudo giram em torno de até 2 salários mínimos, um total de $86 \%$ se somados os que recebem um salário e os que recebem dois, ou seja, duas aposentadorias por família, tendo em vista que $65,3 \%$ vivem com cônjuge ou companheiro (a). Apenas $11,5 \%$ se encontram financeiramente acima disto.

Tabela 3 - Qual Sua Renda Mensal?

\begin{tabular}{c|c|c}
\hline $\begin{array}{c}\text { Qual a sua renda mensal } \\
\text { mínimos }\end{array}$ & Número de respostas & Porcentagem \\
\hline $\begin{array}{c}\text { Entre um e dois salários } \\
\text { Até um salário mínimo }\end{array}$ & 108 & 45,8 \\
\hline $\begin{array}{c}\text { Entre dois e três salários } \\
\text { mínimos }\end{array}$ & 97 & 8,9 \\
\hline $\begin{array}{c}\text { Entre três e quatro salários } \\
\text { mínimos }\end{array}$ & 3 & 1,3 \\
\hline Mais de quatro salários \\
mínimos & 3 & 1,3 \\
\hline Sem renda & 1 &, 4 \\
\hline Não respondeu & 3 & 1,3 \\
\hline Total & 236 & 100,0
\end{tabular}

Fonte: Coleta de Dados da pesquisa - 2018.

Observando outro contexto rural, porém distante geograficamente do estudado, mais precisamente no município de Encanto, no Rio Grande do Norte, Aquino e Souza (2007), ao pesquisarem sobre o impacto da previdência rural nesta localidade, encontraram idosos com rendimentos na faixa de 1 a 2 salários mínimos, referente a metade de sua amostra total, que apresentou apenas $6 \%$ de idosos com ganhos acima de 3 salários mínimos. Apesar de uma realidade rural diferente, as faixas de ganhos mensais se assemelham bastante. 0 que novamente ressalta a importância do recebimento da aposentadoria pelos idosos para seus lares. A participação destes na renda familiar é cada vez maior, já no ano de 2007 , em $53 \%$ dos domicílios com idosos do país, mais da metade da renda era fornecida por pessoas de 60 anos ou mais (TAVARES et al, 2011). Augusto e Ribeiro (2006) verificaram que enquanto os aposentados da zona rural podem descansar e desfrutar da aposentadoria, diversas pessoas na família (netos, filhos, entre outros) encontram abrigo sob o benefício do idoso aposentado. Apresentando a tabela 4, se observa o funcionamento da organização financeira dos lares: 
Tabela 4 - Organização Financeira

\begin{tabular}{c|c|c}
\hline Despesas Familiares & Frequência & Porcentagem \\
\hline Divide as despesas & 172 & 72,9 \\
\hline $\begin{array}{c}\text { Único responsável pelas } \\
\text { despesas }\end{array}$ & 40 & 16,9 \\
\hline $\begin{array}{c}\text { Maior responsável pelas } \\
\text { despesas }\end{array}$ & 11 & 4,7 \\
\hline Não contribui financeiramente & 9 & 3,8 \\
\hline Ajuda quando pode & 3 & 1,3 \\
\hline Não respondeu & 1 & 0,4 \\
\hline Total & 236 & 100,0 \\
\hline
\end{tabular}

Fonte: Coleta de Dados da pesquisa - 2018.

Há uma considerável parcela que se responsabiliza unicamente pelas despesas, 16,9\%, porém a grande maioria $72,9 \%$ idosos dividem as suas despesas com outras pessoas. Levando em conta os dados da tabela 3 sobre a renda mensal, onde a maioria possui renda referente a duas aposentadorias por residência e que $65,3 \%$ estão casados ou ajuntados, se pode dizer que os casais dividem suas despesas com os ganhos da aposentadoria.

Em um estudo realizado no município de Viçosa, Minas Gerais, por Tavares et al. (2011) com 65 idosos rurais, é demonstrado que $80 \%$ dos aposentados eram responsáveis por, no mínimo, metade da renda de suas famílias. Embora a renda da aposentadoria para estes seja considerada uma ajuda, ela é imprescindível para a sobrevivência das famílias rurais, o que denota, em muitos casos, situação de dependência. Os aposentados acabam arcando com a maior parte das despesas familiares e os motivos que levam a estas situações de dependência, segundo Tavares et al. (2011) são os problemas econômicos, familiares, altas taxas de desemprego do país e a baixa remuneração, independente de os filhos coabitarem ou não com os idosos.

Além disso, estes autores revelam que na percepção dos idosos, contribuir para a manutenção econômica de suas famílias é uma obrigação. Dentre os moradores dos domicílios chefiados por aposentados, estão filhos e netos que retiram parte do seu sustento dos benefícios pagos mensalmente aos idosos. Estes dependentes, que geralmente não contam com uma fonte de renda fixa e sobrevivem com a ajuda dos pais e/ou avós, fazem parte de um conjunto populacional que pode ser denominado de "beneficiários indiretos" da Previdência Social Rural (OLIVEIRA; AQUINO, 2017).

Esta dependência gerada no âmbito familiar por filhos, netos, irmãos sobre membros da família que recebem algum tipo de aposentadoria podem acabar com os efeitos esperados de redução da pobreza no meio rural. Na tabela 6 , os resultados são referentes ao questionamento se o dinheiro que estes idosos recebem é suficiente para satisfazer as suas necessidades:

Tabela 5 - Você tem dinheiro suficiente para satisfazer suas necessidades?

\begin{tabular}{c|c|c}
\hline $\begin{array}{c}\text { Você tem dinheiro suficiente } \\
\text { para satisfazer suas } \\
\text { necessidades? }\end{array}$ & Número de respostas & Porcentagem \\
\hline Sim & 152 & 64,4 \\
\hline Não & 84 & 35,6 \\
\hline Total & 236 & 100,0 \\
\hline
\end{tabular}

Fonte: Coleta de Dados da pesquisa - 2018. 
Da amostra total 64,4 consideram sua renda suficiente para suprir seus gastos, mas $35,6 \%$ acenam negativamente. Para uma melhor compreensão deste fenômeno um novo questionamento foi feito realizado para esta última parcela abrangendo a seguinte questão: Para o que falta dinheiro?

Tabela 6 - Para o que falta dinheiro?

\begin{tabular}{c|c|c|c}
\hline $\begin{array}{c}\text { Para o que falta } \\
\text { dinheiro? }\end{array}$ & $\mathrm{N}$ & Porcentagem & Porcentagem de casos \\
\hline Saúde & 98 & $64,5 \%$ & $122,5 \%$ \\
\hline Lazer & 20 & $13,2 \%$ & $25,0 \%$ \\
\hline Moradia & 18 & $11,8 \%$ & $22,5 \%$ \\
\hline Alimentação & 10 & $6,6 \%$ & $12,5 \%$ \\
\hline Transporte & 3 & $2,0 \%$ & $3,8 \%$ \\
\hline Vestuário & 2 & $1,3 \%$ & $1,3 \%$ \\
\hline Todas as & 1 & $0,7 \%$ & $190,0 \%$
\end{tabular}

Fonte: Coleta de Dados da pesquisa - 2018.

Partindo novamente de uma análise de frequência das várias respostas dos idosos, fica evidente que a saúde é o quesito que mais demanda financeiramente (122,5\% de respostas), dentro deste quesito estão os altos gastos com medicamentos e os custos com os planos de saúde $(61,9 \%$ da amostra total não possui nenhum plano de saúde). Na pesquisa realizada por Bitencourt e Dalton (2016) é possível verificar que a aposentadoria rural dos idosos se destinam em grande parte para a aquisição de medicamentos. Alguns medicamentos não são fornecidos pelo Sistema Único de Saúde (SUS), então para muitos idosos não há outra saída a não ser pagarem do próprio bolso. Nesta amostra a maioria também não possui plano de saúde, então quando há necessidade de uma consulta e esta não é fornecida pelo SUS, é preciso pagar o acesso ao serviço privado. Na pesquisa do município de Viçosa, Minas Gerais, por Tavares et al. (2011), 16,09 \% da renda também é destinada a saúde e o agravante aqui é que além dos gastos com medicamentos há os gastos com deslocamento, já que os tratamentos são realizados fora do município, ou longe dos espaços rurais, que não são bem assistidos pelos serviços de saúde.

Em menor número, a alimentação também aparece como uma necessidade, porém muitos idosos possuem uma produção de subsistência, uma horta e alguns animais na propriedade, o que supre eventuais faltas de recursos. A produção familiar e o arrendamento de terras, auxiliam a complementar a renda recebida pela aposentadoria rural. Receber o benefício não significa parar de trabalhar ou produzir para os idosos, essa ideia pode até estar enraizada na cultura do senso comum, pois antigamente não havia necessidade de continuar trabalhando após se aposentar, mas a realidade atual é diferente (BULLA; CAEFER, 2003). Não somente em função de algumas carências como as já citadas, mas também por tradição no campo, os homens tendem a trabalhar até idades avançadas, realizando pequenas tarefas no ambiente doméstico, no trato com os animais e nos cuidados com as hortas que mantém (MORAIS; RODRIGUES; GERHARDT, 2008).

Dos beneficiários da Previdência Rural no município de Encanto, no Rio Grande do Norte, 30\% ainda exercem alguma atividade produtiva ou ocupação e mais da metade trabalham por conta própria, ou seja, 
trabalham em suas terras e utilizam os rendimentos obtidos para complementar a renda domiciliar (AQUINO; SOUZA,2007).

Atualmente, há este movimento por parte dos idosos de luta pelos seus espaços e direitos no mercado de trabalho, indo ao encontro desta perspectiva de uma renda extra, ou, para não entrarem em uma rotina monótona e estereotipada ou ainda, simplesmente, por permanecer em uma ocupação em que se sintam reconhecidos e que gostem de realizar. Desde de 2016, o governo brasileiro prevê uma Reforma da Previdência, instaurando uma idade mínima para aposentadoria (65 anos), sem distinção de raça ou gênero. Levando em conta a longevidade da população atualmente, que aumentou de 48 anos em 1960 para 73,4 anos em 2010 (DERROSSO; OLIVEIRA, 2018 Apud CONSTANZI; ANSILIERO, 2017; ZYLBERSTAJN et al., 2017). Isso nos leva à discussão da inserção da pessoa idosa no mercado de trabalho, mesmo depois da aposentadoria, o que pode ser uma tarefa difícil devido aos preconceitos e estereótipos produzidos sobre a velhice, em que os empregadores podem considerar os idosos como incapazes ou lentos demais para realizarem determinadas atividades no mercado de trabalho (CAMARANO, 2016).

Para Maranhão e Filho (2018) o grande desafio para a reforma na previdência rural encontra-se na heterogeneidade socioeconômica da população rural brasileira, presente na dispersão dos níveis de produtividade, bem como, das relações de trabalho e remuneração. A maior parcela da população beneficiária rural brasileira define-se como segurado especial e ao contrário da população urbana, os benefícios rurais foram, em sua maioria, concedidos por via judicial, expressando uma falha do governo em termos de equilibrar receitas e despesas na estrutura do mercado de trabalho rural.

Qualquer reforma da previdência deverá, além de reorganizar a legislação em função das mudanças demográficas, levar em consideração o progresso técnico, que se faz presente em todos os setores da economia, não somente no setor rural, de forma a elevar a massa de contribuição da previdência (CAMARANO; FERNANDES, 2016). Outro aspecto a ser considerado, diz respeito à idade mínima e ao tempo de contribuição, tanto para homens como para mulheres. Uma proposta de aumento da idade mínima independente do gênero e da localidade de residência desconsidera as grandes diferenças de inserção da mulher no mercado de trabalho, bem como, as diferenças de esperança de vida nos vários estados do país. Na medida em que envelhecer no Nordeste é muito diferente do que na região sul, onde a expectativa de vida tem uma diferença de 15 anos em relação a do Nordeste (CAMARANO; FERNANDES, 2016). 0 que pode acontecer é que, sendo fixada uma idade mínima alta num país com tantas diferenças como o Brasil, sem considerar as desigualdades regionais, leve a uma parcela da população a não conseguir se aposentar (LOURENÇO; LACAZ; GOULART, 2018).

0 grau de dependência das pessoas idosas é em boa parte, determinado pelo fornecimento de rendas por parte do Estado. Como visto anteriormente, grande parte da renda familiar no meio rural depende da aposentadoria do idoso, sugerindo que quando se reduzem ou se aumentam os benefícios previdenciários, o Estado não está simplesmente atingindo indivíduos, mas uma parcela importante dos rendimentos de famílias inteiras (CAMARANO; FERNANDES, 2016).

\section{CONSIDERAÇÕES FINAIS}

Aspirando contribuir com o aprofundamento dos estudos relacionados à temática do envelhecimento no meio rural, o presente trabalho procurou analisar as características socioeconômicas do município rural de Santa Cruz do Sul. De modo geral, esta investigação permitiu identificar que a economia dos idosos rurais do município 
se baseia em sua maior parte nas aposentadorias recebidas pela previdência social. Elas exercem um papel fundamental na vida dos idosos, já que sem essa renda seria muito mais difícil encarar a velhice no campo.

A figura do aposentado rural é central quando se fala em renda familiar neste espaço, pois com as adversidades da lavoura e os índices de desemprego, muitas vezes a única esperança da família é depositada neste idoso, que, com um valor assegurado, por mais que seja um valor mínimo, atualmente de $\mathrm{R} \$ 998,00$ mensais, se responsabiliza por abastecer o lar.

Para, além disso, há a situação da falta de dinheiro para suprir algumas necessidades básicas, principalmente, no que diz respeito à saúde e alimentação. Sem as rendas extras, é muito difícil os idosos arcarem com estes gastos, assim, deve-se fazer uma reflexão acerca desta necessidade de complementar a renda, pois em algum momento devido à idade avançada ou as condições de saúde, estes idosos não poderão mais realizar atividades laborais no campo, então como obterão os recursos necessários para manter uma qualidade mínima de vida?

0 fato de as famílias dependerem tanto das aposentadorias rurais dos idosos é também um fator preocupante, haja vista que se não fosse pelas mesmas, o índice das rendas familiares cairia e muito, então qualquer mudança governamental realizada nestes benefícios, deve ser extremamente cautelosa e bem analisada. Assim, este e os demais estudos sobre o contexto rural, devem ser levados em consideração pelos órgãos públicos e pelos gestores de políticas públicas em qualquer proposta de reforma constitucional relacionada à seguridade social no país.

\section{AGRADECIMENTOS}

Agradecemos à Universidade de Santa Cruz do Sul (UNISC), ao Conselho Nacional de Desenvolvimento Científico e Tecnológico (CNPQ), a Fundação de Amparo à Pesquisa do Estado do Rio Grande do Sul (FAPERGS) e ao Conselho Municipal do Idoso de Santa Cruz do Sul, que possibilitaram a realização da pesquisa. Os autores também agradecem aos profissionais da Estratégias Saúde da Família dos distritos e aos idosos que se voluntariam a participar da pesquisa.

\section{REFERÊNCIAS}

ALCÂNTARA, Adriana. Envelhecer no contexto rural: a vida depois do aposento. In: ALCÂNTARA, A.; CAMARANO, A.A; GIACOMIN, K.C. (Org). Políticas Nacional do Idoso: velhas e novas questões. Rio de Janeiro: IPEA, 2016.

AQUINO, J. R.; SOUZA, R. C. Impactos socioeconômicos da Previdência Rural no Brasil: um estudo de caso no município de Encanto/RN. Anais do XLV Congresso da Sociedade Brasileira de Economia, Administração e Sociologia Rural, 2007. Disponível em: < http://www.sober.org.br/palestra/6/663>. Acesso em: 25 jan. 2019.

AUGUSTO, H. A. \& RIBEIRO, E. M. O idoso rural e os efeitos das aposentadorias rurais no domicílio e no comércio local: 0 caso de Medina, nordeste de Minas. Anais do Encontro Nacional de Estudos Populacionais, 2006. Disponível em: < http://www.abep.org.br/publicacoes/index.php/anais/article/download/1638/1601>. Acesso em: 13 fev. 2019.

BITENCOURT, R. O. M. de; DALTO, F. A. S. A internalização da Previdência Social Rural na autonomia e no consumo dos idosos: um estudo de caso. Revista de Estudos Sociais, Mato Grosso, v.18, n. 37, p. 42-57,2017. Disponível em: <http://periodicoscientificos.ufmt.br/ojs/index.php/res/article/view/3161>. Acesso em: 09 fev. 2019. 
BRITO, Fausto. A população na cena política: o debate sobre as consequências do envelhecimento populacional. In: ANDRADE, M. V.; ALBUQUERQUE, E. da M. (Ed.). Alternativas para uma Crise de Múltiplas Dimensões, Belo Horizonte: CEDEPLAR - UFMG, 2018.

BULLA, L.C.; KAEFER, C.O. Trabalho e aposentadoria: as repercussões sociais na vida do idoso aposentado. Revista Textos e Contextos, Porto Alegre, v.2 n. 2, 2003. Disponível em:

<http://revistaseletronicas.pucrs.br/ojs/index.php/fass/article/view/957/737>. Acesso em: 09 fev. 2019.

CAMARANO, A A.; FERNANDES, D. A previdência Social Brasileira. In: ALCÂNTARA, A. de 0.; CAMARANO, A. A.; GIACOMIN, K. C. (Orgs.). Política Nacional do Idoso: velhas e novas questões. Rio de Janeiro: Ipea, 2016.

DERROSSO, Giuliano; OLIVEIRA, Mariana. A Inserção de Idosos no Mercado de Trabalho de Foz do Iguaçu. Revista Ciências Humanas - Educação e Desenvolvimento Humano. Taubaté, v. 11, n. 1, p. 47 - 61, 2018. Disponível em: <https://www.rchunitau.com.br/index.php/rch/article/view/428/249 > Acesso em: 24 ago. 2018.

IBGE - Instituto Brasileiro de Geografia e Estatística. Nível territorial - Distrito. Rio de Janeiro: IBGE.2010. Disponível em:

<Https://sidra.ibge.gov.br/Acervo?nivel=10\&unidade=431680807\#/S/Q>. Acesso em: 07 fev. 2019.

IBGE - Instituto Brasileiro de Geografia e Estatística. Pesquisa Nacional por Amostra de Domicílios Contínua. Rio de Janeiro: IBGE .2017. Disponível em:

<Https://agenciadenoticias.ibge.gov.br/media/com_mediaibge/arquivos/a7d023687b221aafb0364f56cad943 67.pdf > Acesso em: 28 jan. 2019.

LOURENCO, E. Â. de S.; LACAZ, F. A. de C.; GOULART, P. M. Crise do capital e o desmonte da Previdência Social no Brasil. Serviço Social e Sociedade, São Paulo, n. 130, p. 467-486, 2017. Disponível em:

<http://www.scielo.br/scielo.php?script=sci_arttext\&pid=S0101-66282017000300467\&lng=en\&nrm=iso>. Acesso em: 9 fev. 2019

MARANHÃO, R. L. A.; FILHO, José Eustáquio Ribeiro Vieira. Previdência Rural no Brasil. Rio de Janeiro: Ipea, 2018.

MORAIS, E. P. de; RODRIGUES, R. A. P; GERHARDT, T. E. Os idosos mais velhos no meio rural: realidade de vida e saúde de uma população do interior gaúcho. Texto \& Contexto - Enfermagem, v. 17, n.2, p. 374-383, 2008. Disponível em: <https://dx.doi.org/10.1590/S0104-07072008000200021>. Acesso em: 28 jan. 2019.

OLIVEIRA, R. P.; AQUINO, J. R. A previdência rural e sua importância para as famílias pobres no Nordeste: resultados de um estudo de caso no Rio Grande do Norte. Revista Econômica do Nordeste, Fortaleza, v. 48, n. 1, p. 115-130, 2017. Disponível em:

<https://www.bnb.gov.br/projwebren/Exec/artigoRenPDF.aspx?cd_artigo_ren=1697>. Acesso em: 20 dez. 2018. ORGANIZAÇÃO MUNDIAL DA SÁUDE. Relatório Mundial de Envelhecimento e saúde- Brasília: Organização PanAmericana da Saúde, 2015.

SOUZA, E. L. C.; STADUTO, J. A. R.; KRETER, A. C. Previdência rural e mulher: uma análise interregional a partir da perspectiva de gênero. Revista da ABET, João Pessoa, v. 16, n. 1, p. 119-137, 2017. Disponível em:

<http://www.periodicos.ufpb.br/ojs/index.php/abet/article/view/36031/18556>. Acesso em: 12 jan. 2019.

TAVARES, Vivian, et al. Interfaces entre a renda dos idosos aposentados rurais e o contexto familiar. Textos e Contextos. Porto Alegre, v. 10, n. 1, p. 94 - 108, 2011. Disponível em:

<http://revistaseletronicas.pucrs.br/ojs/index.php/fass/article/view/8725 >. Acesso em: 23 jan. 2019.

TONEZER, C.; TRZCINSKI, C.; MAGRO, M. Dal. As Vulnerabilidades da Velhice Rural: Um Estudo de Casos Múltiplos no Rio Grande do Sul. Desenvolvimento Em Questão, ljuí, v.15, n.40, p.7-38.2017 Disponível

em:https://doi.org/10.21527/2237-6453.2017.40.7-38. Acesso em 18 jan.2019 